Psicologia \& Sociedade; 16 (1): 37-49; Número Especial 2004

\title{
ATUANDO EM CONTEXTO: O PROCESSO DE AVALIAÇÃO NUMA PERSPECTIVA INCLUSIVA
}

\author{
Denise Meyrelles de Jesus \\ Universidade Federal do Espírito Santo
}

RESUMO: Para que a diversidade possa se fazer presente, a base da educação de alunos com necessidade educativas especiais (n.e.e.) precisa se construir numa abordagem de apoio colaborativo. Neste relato buscamos evidenciar o processo de repensar a avaliação educacional de um aluno da segunda série. A partir do trabalho com a professora e a pedagoga, definimos aspectos a serem avaliados e um projeto educativo para o aluno a ser trabalhado na sala de aula. $\mathrm{O}$ estudo deste caso desencadeou uma atitude de mudança quanto à avaliação nos profissionais das séries iniciais, trazendo à tona inúmeras questôes sobre o processo de avaliação naquela escola. Os dados nos mostraram a processualidade do trabalho e como é difícil passar de uma avaliação diagnóstica por especialistas para uma avaliação pedagógica das condições de ensino-aprendizagem.

PALAVRAS-CHAVE: avaliação educacional, necessidades educacionais especiais, educação especial.

\section{EVALUATION IN AN INCLUSIVE PERSPECTIVE: BUILDING TOGETHER WITH TEACHERS}

ABSTRACT: In order to make diversity present, the basis of education for students with special educational necessities needs to be built in an approach of collaborative support. In this text we search to evidence the process of rethinking the educational evaluation of a second grade student. From a work with the teacher and the pedagogue, we defined the aspects to be evaluated and an educative project for the student, to be worked in the classroom. The study of this case sets off an attitute of change towards evaluation in the initial grades, bringing into the open several issues on the evaluation process of that school. Data show us the work processuality and how it is difficult to go from a specialist's diagnostic evaluation to a pedagogic evaluation of the teach-learning conditions. 
Jesus, D. M

"Atuando em contexto: o processo de avaliação numa perspectiva inclusiva"

KEYWORDS: educational evaluation, special educational necessities, special education.

Nesse artigo procuramos refletir com os profissionais da escola sobre as suas experiências. Partimos do seu saber-fazer para a construção de um novo modo de lidar com a realidade. Pretendemos avançar na problematização/compreensão da necessidade da escola como espaço social, provocar mudanças para incluir todos os seus alunos, inclusive aqueles que demandam maior apoio no processo educacional.

Concordamos com Figueiredo (2002, p. 68), quando sugere que, para

...efetivar a inclusão é preciso [...] transformar a escola, começando por desconstruir práticas segregacionistas. [...] a inclusão significa um avanço educacional com importantes repercussöes politicas e sociais visto que não se trata de adequar, mas de transformar a realidade das práticas educacionais.

Para que a diversidade humana possa se fazer presente como valor universal, a escola precisa assumir uma postura de construtora da igualdade, visando a incluir na tessitura social aqueles que vêm sendo sistematicamente excluídos.

Nesse sentido, ganham especial relevância os discursos e ações dos professores, porque, em última instância, são eles que, no meio de seus medos, dúvidas, ansiedades, disponibilidades, acolhimentos e possibilidades, assumem os alunos em suas salas de aula. São as práticas pedagógicas aí desenvolvidas que poderão construir ou não no sentido da aquisição do conhecimento por todas as crianças, sejam ditas "normais ou com necessidades educativas especiais".

Pesquisas recentes (FIGUEIREDO, 2002; MANTOAN, 2002; Jesus et al., 2000) corroboram os resultados observados na primeira fase deste estudo. Os professores manifestam que têm dificuldades em trabalhar com alunos com algum tipo de deficiência e, mais que isso, muitos não acreditam em sua capacidade de mudar esse quadro. Concordamos com Figueiredo (2002, p. 76), quando 
analisa: "...isto decorre da dificuldade de trabalhar pedagogicamente com a diversidade".

Assim sendo, faz-se necessário trabalhar com os profissionais da educação de maneira que eles, sendo capazes de compreender e refletir sobre as suas práticas, sejam também capazes de transformar lógicas de ensino.

Acreditamos que a qualificação do professor se constitui numa forma de fortalecimento da qualidade do atendimento dos alunos no seu conjunto e da crença dos professores de que podem construir novas alternativas e desenvolver novas competências (NÓVOA, 1992).

Nossa perspectiva era trabalhar no cotidiano da prática pedagógica da escola, por meio de estratégias variadas, tendo como objetivo produzir uma "reflexão autoformadora" (NÓVOA, 2000).

Tomamos, como princípio básico, a necessidade de preparação dos profissionais da educação para uma prática reflexiva, para a inovação e a cooperação. Nesse sentido, faz-se necessária uma "escola reflexiva”, ou seja, “...uma organização, que continuamente se pensa a si própria, na sua missão social e na sua organização, e confronte-se com o desenrolar de sua atividade em um processo heurístico simultaneamente avaliativo e formativo" (ALARCÃO, 2001, p. 11), ou seja, uma "organização aprendente", aquela "que se pensa e que se avalia em seu projeto educativo".

As organizaçôes aprendem quando têm capacidade para ser sensíveis às necessidades do meio, quando são capazes de utilizar o saber adquirido para melhorar as suas possibilidades de resposta e de responder "criativamente" quando essas são detectadas (BOLÍVAR, 1997).

Em uma "organização aprendente", os seus membros devem ser incentivados e mobilizados para a participação, a construção, o diálogo, a reflexão, a iniciativa e a experimentação.

$\mathrm{Na}$ escola todos são atores, mas os professores são atores de "primeiro plano" e, conseqüentemente, devem-se intensificar os esforços para que lhes sejam garantidas as orientaçōes necessárias ao exercício da profissão docente e que, por outro lado, os professores tomem consciência da sua própria profissionalidade em termos individuais e coletivos (ALARCÂO, 2001).

A complexidade dos problemas que se colocam à escola na atualidade exige cooperação, olhares multidimensionais e uma ati- 
Jesus, D. M.

"Atuando em contexto: o processo de avaliação numa perspectiva inclusiva"

tude de investigação na ação e pela ação. Por outro lado, “...exige do professor a consciência de que a sua formação nunca está terminada e das chefias e do governo, a assunção do princípio de formação continuada" (ALARCÃO, 2001, p. 24).

Foi nesse sentido que desenvolvemos um projeto de formação-intervenção. E é a dinâmica e complexidade de parte desse processo que relatamos neste trabalho.

Nosso estudo foi conduzido numa escola pública municipal de ensino fundamental de Vitória. Esta escola se constituia em unidade pólo, ou seja, não só atendia os alunos com necessidades educativas especiais, mas também, oferecia atendimento especializado aos alunos de outras 4 unidades de ensino localizadas na regiáo.

A escola localiza-se em região de periferia urbana e atendia alunos oriundos de famílias de baixíssimo nível sócioeconomico.

Frederico, cujo caso tomamos como ponto de partida de nossas discussões, era aluno da segunda série e estava com 9 anos. Sua professora estava concluindo o curso de Pedagogia e tinha mais de 10 anos de experiência de magistério, inclusive como "especialista" em educação especial.

\section{PROCESSO DE AVALIAÇÃO NUMA PERSPECTIVA INCLUSIVA}

A professora Maria havia solicitado auxílio na tentativa de avaliar o processo de aquisição da leitura e escrita do aluno Frederico.

No horários de planejamento, buscamos saber mais sobre o aluno. Ela afirmou que “...se tratava de um aluno pré-silábico, meio que 'empacado' aí... gostaria de material para que ele supere esta fase". Expôs, ainda, como vinha trabalhando com o aluno e reconhecia progressos na oralidade e na compreensão da função da escrita. Além disso, também estava mais próxima do grupo "depois das intervençôes na sala". Concluiu: "Temos que respeitar o ritmo do aluno... mas acho que ele pode andar mais".

Elaboramos, a partir da literatura, um breve roteiro de pontos que poderíamos estar avaliando com o aluno. ${ }^{1}$

Por meio de uma série de atividades, tentamos avaliar o aprendizado de Frederico quanto aos itens colocados. Tivemos dois en-

1 Esses pontos consistiam: (1)realismo nominal lógico; (2) reconhecimento do próprio nome; (3) leitura de símbolos; (4) hipótese sobre a escrita; (5) narração e continuidade de histórias; (6) interpretação de textos orais; (7) observação de semelhanças e diferenças em palavras e (8) hipóteses lingüísticas. 
contros e a professora participou do primeiro. No segundo encontro, não havia quem assumisse a turma, por isso ela não pôde comparecer.

Após o segundo encontro com o aluno, juntamente com a pedagoga e a professora, propusemos um projeto educativo específico para Frederico, para ser trabalhado na sala de aula e no laboratório pedagógico da escola. Todo o grupo da escola tinha conhecimento de que a avaliação estava sendo realizada e que daí surgiria uma proposta. ${ }^{2}$

O grupo tinha uma série de questões sobre como detalhar cada um dos objetivos. Apresentamos um conjunto de exemplos bem como uma bibliografia básica, disponível na biblioteca da escola.

A maioria daqueles profissionais tinha alguns alunos que poderiam "se beneficiar" daquela proposta. Analisamos que a proposta havia sido elaborada para um aluno específico, e a partir de uma a avaliação mais sistemática. Voltamos a discutir a relevância de um

2 A proposta de trabalho pedagógico para Frederico consistia em: (1) Praticar leitura de símbolos e sinais globais em contextos familiares.(2) Expor o aluno a experiências, visando a analisar realismo nominal lógico.(3) Brincadeira de faz-de-conta (que incluía usar objetos que representem o real; usar objetos que não representam o real; apresentar situações sem a utilização de objeto, apenas gestos). (4)Simbolização (incluindo ler para a criança o significado de alguns símbolos, ler para a criança alguns índices). (5) Escrita como registro (explorar objetos - cor, forma, cheiro, sabor, para que serve; relacionar oralmente alguns objetos apenas nomeando-os e pedir que a criança reconstitua a lista). (6) Elaborar frases/textos oralmente com diferentes palavras e o adulto grafa. Ler os textos com a criança.(7) Levar a criança a ler gravuras, obras de arte, ilustraçôes (da própria escola), marca de produtos e textos diversificados de livros, de revistas, jornais, folhetos, cartazes, etc. Expor o aluno ao máximo de material escrito. (8) Ler livrinhos de história com a criança para ela fazer interpretação oral; solicitar que ela reconte a história; grafar para ela a síntese; solicitar que reconheça palavras. (9) Mostrar a seqüência de histórias, a partir de pranchas. (10)Fazer jogo de correspondência entre palavras e desenhos. (11) Apresentar uma série de desenhos e propor que a criança escreva palavras. Colocar as mesmas palavras no desenho e propor que ele desenhe. (12)Testar hipóteses lingüísticas. (13)Recortar palavras em revistas, livros, textos, jornais.(14)Trabalhar com letras do próprio nome. Incluimos também algumas observações: use recursos variados; utilize vários tipos de materiais; elabore várias atividades diferentes; utilize jogos, desde que tenham objetivos para usá-los; lembre-se de que o entusiasmo do adulto contagia a criança; registre como foi realizada a atividade, como foi o processo e a avaliação do resultado daquele dia. 
Jesus, D. M.

"Atuando em contexto: o processo de avaliação numa perspectiva inclusiva"

plano para o aluno, embora reconhecêssemos a comunalidade daquelas questôes.

No encontro seguinte do grupo, trabalhamos textos sobre a questão da avaliação numa perspectiva inclusiva. Tal tema trouxe muita inquietação, visto que estávamos no final do ano e a decisão sobre aprovar ou não os alunos era iminente.

A discussão do grupo mostrava que a tomada de decisão fazia balançar algumas convicções das professoras.

A professora Eva se colocava: "Eu acho que estou indo no caminho certo. A avaliação deles será de acordo com o nível de desempenho deles. Como você diz... parâmetro de si mesmo! Mas tenho medo, quem vai pegá-los ano que vem na $4^{a}$ série?”.

E a professora Maria ponderou: "Estou convencida que, do ponto de vista formal, eles serão promovidos, embora eu tenha clareza quanto à necessidade de apoio que esses alunos têm. Isto é a função do laboratório e da professora do ano que vem".

Três professoras analisam que os alunos ainda poderiam se beneficiar do projeto de férias. Algo bem específico como a proposta feita para Frederico.

O grupo do laboratório concordou com as colocações, mas insistia que o planejamento da tarefa era das professoras, bem como preparar o "dossiê dos alunos".

Dizíamos que víamos como uma tarefa conjunta, visto que havia uma intervenção realizada no laboratório. As professoras das turmas concordaram e os membros do laboratório não se manifestaram.

No encontro seguinte, trouxemos um texto sobre avaliação que se aproximava da perspectiva da avaliação preconizada na Declaração de Salamanca. O grupo também demandava conhecer o texto dos parâmetros curriculares da área de Educação Especial, no que tangia à avaliação.

Observamos os textos e as análises do material evidenciavam que aqueles princípios eram difíceis de serem incorporados. Havia idas e vindas, e sempre a discussão sobre os professores das séries seguintes.

A diretora procurou mostrar a relevância do projeto "Escola de Férias" para aqueles e também os outros alunos. Buscamos mos- 
trar a importância de relatórios bem elaborados, que servissem de parâmetros para a continuidade do processo, sem considerar a possibilidade de reprovação.

Uma das pedagogas questionou: “...mas não há uma série em que eles ficam melhor encaixados? Quais são os objetivos para os alunos com as necessidades educativas especiais? Quais são os critérios? Não sei, não!".

As professoras das turmas insistiram que tudo aquilo já havia sido dito e que elas estavam definidas, embora precisassem de ajuda nos relatórios.

Reiteramos a possibilidade de realizar um trabalho diferenciado com professores e alunos e enfatizamos como o laboratório pedagógico e os pedagogos poderiam "fazer a diferença". O grupo parecia perplexo. Confirmamos que iríamos ajudá-las a elaborar os "dossiês" dos alunos com necessidades educativas especiais.

Marcamos horários para começarmos os "dossiês" com cada professora. Elas insistiram que a pedagoga do ciclo e uma professora do laboratório deveriam estar presentes. As professoras demandam o seu próprio apoio. No grupo, ainda elaboramos um roteiro comum para ser seguido. ${ }^{3}$

Nos encontros marcados, elaboramos detalhadamente um caso, e as professoras produziram os demais. No segundo encontro com cada uma delas, revimos os relatórios feitos por elas e fizemos sugestōes, quando necessário.

A professora Eva nos questionou: "Você vai ao conselho de classe? Sinto em você o apoio. Às vezes você nem vem aqui na sala mas, eu sei que você está aqui... obrigado pela sua ajuda, em você eu sinto cumplicidade". Reiteramos que estaríamos no conselho de classe final.

$\mathrm{Na}$ reunião definida para acontecer o conselho de classe, estavam presentes as pedagogas do ciclo, as professoras do laboratório e as de $1^{\text {a }}$ a $4^{a}$ série.

3 O Roteiro proposto consistia em: (1)Descrição do caso: síntese dos dados escolares/familiares relevantes. (2) A avaliação do aluno no início do ano letivo. (3) Crescimento escolar ao longo do ano. (4) Potencialidades e interesses. (5) Maiores dificuldades. (6) Atitude diante do processo de escolarização (avaliar mudanças). (7) Recomendaçôes: a) para escola de férias; b) para professores da série seguinte e do laboratório pedagógico. 
Jesus, D. M

"Atuando em contexto: o processo de avaliação numa perspectiva inclusiva"

Foram discutidas questóes gerais relativas ao fato de a Secretaria Municipal da Educação não ter parâmetros claros de aprovação ou não. Analisaram a questão de muitos alunos estarem tendo um bom nível de aprendizado, mas não estarem no nível da série subseqüente. Lembraram que os professores poderiam trabalhar com níveis diversificados, mas questionavam se eles saberiam fazê-lo. A alfabetização parecia ser a grande questão, independentemente da série ou do fato de o aluno apresentar ou não necessidades educativas especiais.

O grupo passou a discutir a situação específica de alguns alunos que apresentavam maiores dificuldades acadêmicas ou socioafetivas. As questões familiares eram sempre trazidas como justificativa da situação escolar do aluno; pouco se analisou a responsabilidade da própria escola.

Para alguns, foi sugerida a inclusão no projeto de férias, enquanto, para outros, o projeto Nova Oportunidade de Avaliação (NOA), ou seja, uma "nova prova " no início do ano letivo seguinte, o que definiria a promoção ou não.

Quanto aos alunos com necessidades educativas especiais, a decisão parecia ser a de promovê-los com a recomendação de escola de férias e de acompanhamento do laboratório pedagógico para a maioria, enquanto alguns poucos (três) poderiam ter acompanhamentos do laboratório de atividades curriculares.

Foram lidos os relatórios e, embora parecesse haver dúvidas quanto à promoção, havia a argumentação de que "alunos com necessidades educativas especiais não deveriam ficar reprovados".

A professora Maria falou de suas dúvidas: "É, confesso... eu ainda tenho muitos conflitos. É melhor deixar ir, em casos extremos volta. Sei não!".

Retomamos à questão da proposta de avaliação da Secretária Municipal da Educação e do MEC. Analisamos que se tratava de assumir responsabilidades pelo aprendizado do aluno no seu nível de desenvolvimento e, assim sendo, a questão da reprovação perdia a conotação que ali vinha sendo posta.

A professora Amélia diz: "Ouvindo tudo isto, estou mudando de idéia. Não vou reprovar Rafael e sim colocá-lo para o projeto de férias. Ele precisa melhorar, mas já está quase com 13 anos e na $4^{a}$ série outra vez!". 
As professoras Maria e Eva pediram para rever o caso de outros alunos ditos normais.

O conselho de classe "terminou" com várias pendências. As professoras queriam repensar os casos, ao que a pedagoga do ciclo comentou: "Vim, já estava tudo certinho... agora... só quero ver quando vou entrar de férias".

A avaliação do aluno parece ainda se constituir numa das questôes mais contraditórias no modelo educacional vigente e modelos que visam a ultrapassá-lo muitas vezes se pegam teimando em propostas nada inclusivas.

Sanches (1996) chama a atenção para o fato de que o diagnóstico educativo, que se constitui na caracterização das aquisições e das dificuldades do aluno, deve ser exaustivo, para que a intervenção vá ao encontro das reais necessidades do aluno.

Assim sendo, buscamos, a partir da noção de demonstração, outra vez, junto com a professora, realizar uma avaliação educativa quanto às "hipóteses lingüísticas" de seu aluno. Como ponto de partida, trabalhamos o referencial teórico trazido pela professora. Construímos com ela uma proposta de intervenção a partir da avaliação educativa inicial e todo o material se constituiu em conteúdo de estudo e discussão do grupo de formação-intervenção.

A avaliação final na escola consiste num momento de impasse. E o conselho de classe final revelou claramente os limites e dificuldades da maioria com as questôes que diziam respeito à avaliação.

Havia dúvidas e medos. A ansiedade se fazia presente e o grupo desejava que uma "instância maior" definisse os critérios a serem seguidos. As professoras demandavam apoio na tomada de decisão, bem como na construção das fichas de avaliação. Nessa perspectiva, elaboramos no grupo um modelo de ficha que pudesse deixar evidente "...o que o aluno sabia, o que deveria saber e uma proposta de programa a ser desenvolvida” (SANCHES, 1996, p. 47).

Os dados nos mostram a processualidade do trabalho e como é difícil passar da abordagem de uma avaliação por especialistas, para uma avaliação das condições de ensino/aprendizagem. "A formação não se faz antes da mudança, faz-se durante, produz-se nesse esforço de inovação e de procura dos melhores percursos para a transformação da escola (NÓVOA, 1995, p. 28). 
Jesus, D. M

"Atuando em contexto: o processo de avaliação numa perspectiva inclusiva"

Partimos do pressuposto de que a transformação da escola consiste em condição para o desenvolvimento da perspectiva de uma educação para todos e de que essa transformação da escola se constitui numa educação para todos. $\mathrm{E}$, também, que essa transformação se sustenta no profundo conhecimento da cultura da escola, em que seus membros tenham consciência de si próprios, de suas ações e do seu ambiente.

Tomamos como princípio básico a necessidade de preparação dos profissionais de educação para uma prática reflexiva, para a inovação e a cooperação. $\mathrm{O}$ profissional reflexivo mantém um compromisso "...no debate social sobre as finalidades da escola e de seu papel na sociedade" (PERRENOUD, 1999, p. 12).

Um fator decisivo na modificação da escola consiste em transformar-se numa "organização aprendente", aquela que se pensa e que se avalia em seu próprio projeto educativo. Bolívar (1997, p. 82) nos alerta que a escola só será uma “...unidade básica de formação e inovação se nela houver espaço para a aprendizagem institucional”.

O mesmo autor argumenta que as organizaçóes aprendem quando têm capacidade para ser sensíveis às necessidades do meio e de responder criativamente.

Esse processo depende de redes de colaboração que existem entre os seus membros. A aprendizagem em equipe é a chave para a organização se desenvolver como um conjunto. Os seus membros devem ser incentivados e mobilizados para a participação, a co-construção, o diálogo, a reflexão, a iniciativa e a experimentação.

Assim, buscamos pela via de a formação-intervenção contribuir no sentido de criar condiçóes de mudanças das práticas pedagógicas, considerando os profissionais da escola como atores de "primeiro plano" (ALARCÃO, 2001).

Entendíamos que o aperfeiçoamento do pessoal docente se constitui em suporte à educação inclusiva e que a formação continuada permanente, tomando por base a realidade concreta onde se dão aprendizagens, é o seu locus privilegiado.

Alguns alunos, por razões diferentes, são colocados como protótipos do imaginário que povoa as representações dos profissionais da escola. Para "o bem" ou para "o mal", são colocados no lugar de representantes de uma determinada "classe de sujeitos". 
Aprofundarmo-nos no estudo de um caso pode representar uma possibilidade de todos da equipe escolar se implicarem no conhecimento, reflexão e prática alternativa, visando modificar uma situação em processo.

Nesse sentido, pudemos auxiliar os profissionais da escola a verem a si próprios e aos seus colegas como "solucionadores das questôes coletivas" que emergem no cotidiano (PORTER, 1997).

Nossa perspectiva teórica é de que o estudo de caso contribuiu para a construção coletiva do conhecimento que vai além da mera descrição e conforme nos sugere Alarcão (2003, p. 37) "representa conhecimento teórico e assume valor explicativo", visto que não há conhecimento de caso sem sua interpretação teórica.

A análise casuística de episódios reais apresenta-se-me como uma estratégia de grande valor formativo. Permite desocultar situações complexas e construir conhecimento ou tomar consciência do que a final já se sabia (ALARCÃO, 2003, p. 52).

No entanto, a reflexão crítica “... precisa de ser sistemática nas suas interrogações e estruturante dos saberes dela resultantes", o que pressupõe o que Alarcão (2003, p. 44) nomeia de triplo diálogo: um diálogo consigo próprio, um diálogo com os outros, inclusive os que construíram conhecimentos que são referência e o diálogo com a situação.

Nos episódios relatados e em suas discussões, cremos ter enunciado uma possibilidade de atuação, dentre muitas outras. Não há fechamentos possíveis para tais empreendimentos. Todos nós envolvidos aprendemos e vimos muitas de nossas certezas entrarem em turbulência. Mas já não estamos sós, estamos todos implicados. Aos profissionais da educação fica a questão: como lidar com a diversidade, o desejo, a incerteza, o movimento, o desafio, o saber?

Quem sabe não deveríamos exercitar velhas artes de infância, como a teima $[. .$.$] teimar um determinado objetivo, perseguir per-$ severantemente um determinado propósito, apostar corajosamente no que acredita e, com isso, conseguir fazer pequenos deslocamentos, ou seja, ir onde ninguém está esperando, penetrar em lugares desconhecidos, surpreender e surpreender-se... (EIZIRIK, apud JESUS, 1995, p. 2). 
Jesus, D. M.

"Atuando em contexto: o processo de avaliação numa perspectiva inclusiva"

\section{REFERENNCIAS}

ALARCÃO, I. (Org.). Escola reflexiva e nova racionalidade. Porto Alegre: Artmed, 2001.

ALARCÃO, I. Professores reflexivos em uma escola reflexiva. São Paulo: Cortez, 2003.

BOLÍVAR, A. A escola como organização que aprende. In: CANÁRIO, Rui. (Org.). Formação e situações de trabalho. Porto: Porto Editora, 1997. p. 79-100.

FIGUEIREDO, R. V. Políticas de inclusão: escola-gestão da aprendizagem na diversidade in ROSA de E. G. e SOUZA V. C. (org.) Políticas organizativas e curriculares, educação inclusiva e formação de professores. Rio de Janeiro: DP\&A Editora, 2002.

JESUS, D. M.; PEREIRA, A. M.; SOUZA, R. G. S. Construindo uma prática de formação inicial em educação especial. Caderno de Pesquisa em Educação-PPGE/UFES, Vitória, v. 2, n. 12. p. 56-79, dez. 2000.

JESUS, D.M. Educação Inclusiva: construindo novos caminhos. Vitória: Universidade Federal do Espírito Santo, Programa de PósGraduação em Educação, 2002.

MANTOAN, M. T. E. Produção de conhecimento para abertura das escolas às diferenças: a contribuição do LEPED (Unicamp) In: ROSA de E. G. e SOUZA V. C. (org.) Políticas organizativas e curriculares, educação inclusiva e formação de professores. Rio de Janeiro: DP\&A Editora, 2002.

NÓVOA, A. Formação de professores e profissão docente. In: Nóvoa, A. (Org.). Os professores e sua formação. Lisboa: Nova Enciclopédia, 1992. p. $97-121$.

NÓVOA, A. Formação de professores e profissão docente. In: Nóvoa, A. (Org.). Os professores e sua formação. Lisboa: Publicações Dom Quixote - Instituto de Inovação Educacional, 1997. p. 97-121. 
NÓVOA, A. (Org.). Vidas de professores. Porto: Porto Editora, 2000.

PERRENOUD, P. Construindo as competências desde a escola. Porto Alegre: Artes Médicas, 1999.

PORTER, G. Organização das escolas: conseguir o acesso e a qualidade através da inclusão. In: AINSCOW, M.; PORTER, G.; WANG, M. Caminhos para as escolas inclusivas. Lisboa: Instituto de Inovação Educacional, 1997.

SANCHES, I. R. Necessidades educativas especiais e apoios e complementos educativos no cotidiano do professor. Porto: Porto Editora, 1996.

Denise Meyrelles de Jesus é professora do Programa de Pós-Graduação em Educação da Universidade Federal do Espírito Santo. $O$ endereço eletrônico da autora é: jesusdenise@hotmail.com

Denise Meyrelles de Jesus

Atuando em contexto: o processo de avaliação numa perspectiva inclusiva Recebido: 25/10/2003

$1^{\text {a }}$ revisão: $5 / 3 / 2004$

Aceite final: 12/4/2004 